\title{
Article \\ Study on the Control of Dichloroacetonitrile Generation by Two-Point Influent Activated Carbon-Quartz Sand Biofilter
}

\author{
Xinrui Gui ${ }^{1,2,3}$, Huining Zhang 2,3,*(D), Bixiao Ji ${ }^{2,3}$, Jianqing Ma ${ }^{2,3}$, Meijuan Xu ${ }^{2}$, Yan Li ${ }^{2,3}$ and Ming Yan ${ }^{4}$ \\ 1 Polytechnic Institute, Zhejiang University, Hangzhou 310000, China; 21960557@zju.edu.cn \\ 2 School of Civil Engineering \& Architecture, NingboTech University, Ningbo 315100, China; \\ JiBixiao@nit.zju.edu.cn (B.J.); majq@nbt.edu.cn (J.M.); xmj80@126.com (M.X.); liyanliyan@nbt.edu.cn (Y.L.) \\ 3 Ningbo Research Institute, Zhejiang University, Ningbo 315100, China \\ 4 Ninghai Branch of Ningbo Ecological Environment Bureau, Ningbo 315600, China; yanming7727@126.com \\ * Correspondence: zhanghn@nbt.edu.cn; Tel./Fax: +86-150-5803-3683
}

Citation: Gui, X.; Zhang, H.; Ji, B.; Ma, J.; Xu, M.; Li, Y.; Yan, M. Study on the Control of Dichloroacetonitrile Generation by Two-Point Influent Activated Carbon-Quartz Sand Biofilter. Membranes 2022, 12, 137. https://doi.org/10.3390/ membranes12020137

Academic Editor: Seonki Lee

Received: 17 December 2021

Accepted: 17 January 2022

Published: 24 January 2022

Publisher's Note: MDPI stays neutral with regard to jurisdictional claims in published maps and institutional affiliations.

Copyright: (C) 2022 by the authors. Licensee MDPI, Basel, Switzerland. This article is an open access article distributed under the terms and conditions of the Creative Commons Attribution (CC BY) license (https:// creativecommons.org/licenses/by/ $4.0 /)$.

\begin{abstract}
Aiming at the problem of highly toxic Nitrogenous disinfection by-products (N-DBPs) produced by disinfection in the process of drinking water, two-point influent activated carbon-quartz sand biofilter, activated carbon-quartz sand biofilter, and quartz sand biofilter are selected. This study takes typical N-DBPs Dichloroacetonitrile (DCAN) as the research object and aromatic amino acid Tyrosine (Tyr), an important precursor of DCAN, as the model precursor. By measuring the changes of conventional pollutants in different biofilters, and the changes of Tyr, the output DCAN formation potential of the biofilters, this article investigates the control of DCAN generation of the two-point influent activated carbon-quartz sand biofilter. The results show that the average Tyr removal rate of the three biofilters during steady operation is $73 \%, 50 \%$, and $20 \%$, respectively, while the average effluent DCAN generation potential removal rate is $78 \%, 52 \%$, and $23 \%$, respectively. The two-point influent activated carbon-sand biofilter features the highest removal rate. The two-point water intake improves the hypoxia problem of the lower filter material of the activated carbon-quartz sand biofilter, and at the same time, the soluble microbial products produced by microbial metabolism can be reduced by an appropriate carbon sand ratio, which is better than traditional quartz sand filters and activated carbon-quartz sand biofilters in the performance of controlling the precursors of N-DBPs.
\end{abstract}

Keywords: activated carbon-quartz sand biofilter; nitrogen-containing disinfection by-products; Dichloroacetonitrile; Tyrosine; drinking water

\section{Introduction}

The disinfectant used in the process of drinking water disinfection will react with most natural organic matter as well as producing harmful Disinfection by-products (DBPs) [1] DCAN, as a typical N-DBPs, has higher cytotoxicity and genetic toxicity compared with other common DBPs. It has been detected many times in the disinfection process and has attracted attention [2,3]; as a result, DCAN was selected as the research object in the experiment. The control of N-DBPs can be divided into source control, process control, and end control, in which source control is an effective control way [4]. Dissolved organic nitrogen (DON) is the main precursor of N-DBPs [5], and the source control of N-DBPs is mainly to remove DON. Compared with natural organics, DON usually has the characteristics of low molecular weight and low electrostatic charge. The removal effect of conventional treatment processes (coagulation, flocculation, sedimentation, and sand filtration) is limited. Srithep et al. [6] evaluated the performance of conventional treatment processes in removing Haloacetonitriles (HANs) precursors and found that they can remove about $28 \%$ of DON, but cannot effectively remove HANs precursors. Cuthbertson et al. [7] found that if biofiltration was used before disinfection, N-DBPs precursors could be effectively removed. The water quality analysis results from Xiang et al. [8] showed that the biofilter 
process has a good effect on the removal of pollutants, especially organic micro pollutants. Therefore, the biofilter process is selected as the focus on source control research.

In recent years, the application of biological filtration in the advanced treatment of drinking water has gradually risen. The effectiveness of biologically active filtration for denitrification and the removal of DBPs precursors has been confirmed in most studies [9], but the current research on the removal of N-DBPs precursors is still in its infancy. The traditional quartz sand filter is difficult to meet the drinking water treatment standards under the condition of the micro pollution of the water source. Moreover, the biological activated carbon process has the problem of microbial leakage; domestic and foreign studies show that the activated carbon-quartz sand biofilter derived from the two can remove organic matter well. In view of this, the activated carbon-quartz sand biofilter is selected to control the generation of DCAN. Zhang et al. [10] showed that the activated carbon-quartz sand biofilter had the best control effect on DON when the activated carbon-quartz sand ratio was 2:8. At the same time, it was found that two-point influent can control the DON concentration more effectively than single-point influent, which is why the two-point influent activated carbon-quartz sand biofilter with activated carbon-quartz sand ratio of 2:8 was selected in the experiment. Amino acid (AA) is an important component of DON in water, accounting for $35 \%$ of DON [11]. Some components of DON, such as aromatic AA, are easy to generate N-DBPs and difficult to remove. Therefore, Tyr, an important precursor of DCAN, is used as a simulated precursor to analyze its changes in the biofilter and explore the control of the biofilter on the formation of DCAN. Due to the high toxicity and commonness of DCAN, the widespread existence of Tyr as an important precursor and some physical characteristics, it is difficult to effectively remove it in the conventional process. Therefore, if the Tyr DCAN precursor can be effectively removed before disinfection, so as to reduce the formation of DCAN, it has a very far-reaching practical significance. At the same time, it also lays a theoretical foundation for the study of the biofilter control of N-DBPs.

\section{Materials and Methods}

\subsection{Test Device}

The test device is shown in Figure 1. The main structure is made of plexiglass, with an inner diameter of $70 \mathrm{~mm}$ and a height of $2000 \mathrm{~mm}$. The biofilter includes a water inlet pipe, a water outlet pipe, a backwash water pipe, a supporting layer, and a filter media layer. The 200-mm-high supporting layer is made of gravel. With particle sizes of $0.5 \sim 1 \mathrm{~mm}$, and $1 \sim 2 \mathrm{~mm}$, respectively, the filler of the filter layer is quartz sand and coconut shell activated carbon. The packing layer of filter A is $1000 \mathrm{~mm}$ quartz sand. The packing layers of filter B and $C$ are both the upper layer of $200 \mathrm{~mm}$ coconut shell activated carbon and the lower layer of $800 \mathrm{~mm}$ quartz sand. According to the design specification of the water plant, the filtration rate of the filter is $8 \mathrm{~m} / \mathrm{h}$, and the influent flow rate is $30 \mathrm{~L} / \mathrm{h}$. Filter $A$ and $B$ are single-point influent, and filter $\mathrm{C}$ is two-point influent, and the two influent points are located at the top and $20 \mathrm{~cm}$ depth from the filter, respectively; the first influent point flow rate is $20 \mathrm{~L} / \mathrm{h}$, and the second influent point flow rate is $10 \mathrm{~L} / \mathrm{h}$. Filter $\mathrm{A}$ and $\mathrm{B}$ are the blank control of filter C. The biofilter is backwashed every $24 \mathrm{~h}$. 


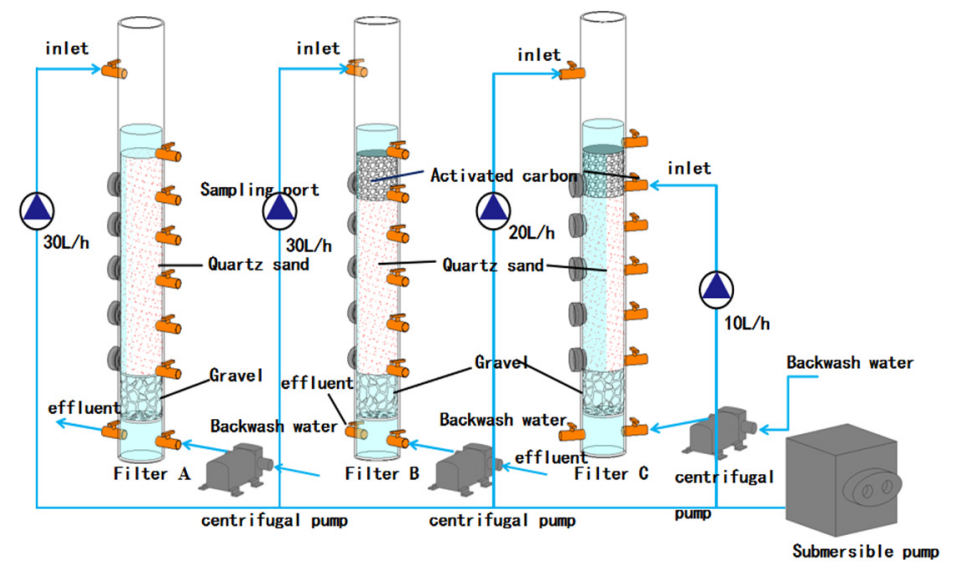

Figure 1. Operating device.

\subsection{Inoculated Sludge and Influent Water Quality}

As the biofilter adopts the method of inoculation and film hanging, the inoculated sludge is taken from the secondary sedimentation tank of the municipal sewage plant. Each filter column is inoculated with $1 \mathrm{~L}$ sludge, and the sludge concentration during inoculation is $2 \mathrm{~g}$ MLVSS/L. The experiment makes use of artificial water distribution, and the water quality of the experiment refers to the effluent from the sedimentation tank of The Ningbo Water Plant. Gu et al. [12] found that the concentration of DON in the source water of Zhejiang, China was $0.9 \sim 1.8 \mathrm{mg} / \mathrm{L}$. Therefore, the dosage of Tyr was selected as $10 \mathrm{mg} / \mathrm{L}$ so that the DON content in the mixed water was $0.61 \sim 1.03 \mathrm{mg} / \mathrm{L}$. The test water quality is shown in Table 1.

Table 1. Influent characteristics during experiment.

\begin{tabular}{|c|c|c|c|c|c|c|}
\hline Index & $\begin{array}{c}\mathrm{NH}_{4}^{+}- \\
\mathrm{N} /\left(\mathrm{mg}^{+} \mathrm{L}^{-1}\right)\end{array}$ & $\begin{array}{c}\mathrm{NO}_{2}^{--} \\
\mathrm{N} /\left(\mathrm{mg}^{-} \mathrm{L}^{-1}\right)\end{array}$ & $\begin{array}{c}\mathrm{NO}_{3}^{--} \\
\mathrm{N} /\left(\mathrm{mg} \cdot \mathrm{L}^{-1}\right)\end{array}$ & $\mathrm{pH}$ & $\mathrm{DO} /\left(\mathrm{mg} \cdot \mathrm{L}^{-1}\right)$ & $\mathrm{DON} /\left(\mathrm{mg} \cdot \mathrm{L}^{-1}\right)$ \\
\hline Content & $0.82 \sim 1.02$ & $0.083 \sim 0.125$ & $0.87 \sim 1.08$ & $7.01 \sim 8.94$ & $6.67 \sim 9.53$ & $0.61 \sim 1.03$ \\
\hline
\end{tabular}

\subsection{Analysis Methods}

Collect influent and effluent samples of three biofilters every day. The water sample is filtered with $0.45 \mu \mathrm{m}$ fiber membrane before analysis, and each water sample is measured 3 times. $\mathrm{NH}_{4}{ }^{+}-\mathrm{N}$ is measured by Nessler's reagent photometric method; $\mathrm{NO}_{2}{ }^{-}-\mathrm{N}$ is measured by $\mathrm{N}$-(1-naphthyl)-ethylenediamine photometric method; $\mathrm{NO}_{3}{ }^{-}-\mathrm{N}$ is measured by UV spectrophotometry; Total nitrogen (TN) is measured by alkaline potassium persulfate digestion UV spectrophotometry; Chemical oxygen demand (COD) is measured by standard potassium dichromate method; Dissolved oxygen (DO) and $\mathrm{pH}$ value are measured by portable analyzer; turbidity is measured by turbidity meter. The biomass is determined by the phospholipid method [13] and the calculation formula of DON is as shown in Equation (1).

$$
\mathrm{DON}=\mathrm{TN}-\mathrm{NH}_{4}{ }^{+}-\mathrm{N}-\mathrm{NO}_{2}{ }^{-}-\mathrm{N}-\mathrm{NO}_{3}{ }^{-}-\mathrm{N}
$$

\subsection{Determination of Tyrosine Content}

Tyr analysis is measured by Hitachi L8900 automatic amino acid analyzer. Put $50 \mathrm{~mL}$ of the water sample into a centrifuge tube, pretreat the water sample with a rotary evaporator, concentrate it for 10 times, inject the mixed amino acid standard working solution and sample determination solution of the same volume into the amino acid automatic analyzer, and calculate the Tyr concentration in the sample determination solution by the external standard method through the peak area. 


\subsection{Determination of Formation Potential of DCAN}

The DCAN formation potential is measured by a fully chlorinated method [14], Shimadzu GC-2030 gas chromatograph is used, sodium hypochlorite solution is acted as a disinfectant, and the effective chlorine dosage is as shown in Equation (2).

$$
C=3 C_{1}+7.6 C_{2}+10
$$

Among them: $\mathrm{C}-\mathrm{Cl}_{2}$ dosage, $\mathrm{mg} / \mathrm{L}$;

$\mathrm{C}_{1}-\mathrm{DOC}, \mathrm{mgC} / \mathrm{L}$;

$\mathrm{C}_{2}-\mathrm{NH}_{3}$ concentration, $\mathrm{mgN} / \mathrm{L}$.

Fully mix after chlorination, adjust the solution to $\mathrm{pH}=7$ with $\mathrm{NaHCO}_{3}$ buffer, store it at $25^{\circ} \mathrm{C}$ away from light and at a constant temperature for $24 \mathrm{~h}$, and then add ascorbic acid to remove the residual chlorine in the water sample. Then take $50 \mathrm{~mL}$ of water sample with a $50 \mathrm{~mL}$ centrifuge tube, add $5 \mathrm{~g}$ of anhydrous sodium sulfate, put it on the vibrator for full shaking for $1 \mathrm{~min}$, add $5 \mathrm{~mL}$ of extractant methyl tert butyl ether for liquid-liquid extraction and enrich DCAN in the water sample. The chromatographic column was used for DCAN detection. The formation potential of DCAN was measured by the modified EPA551.1 method. The sample inlet is $200^{\circ} \mathrm{C}$, the detector is $290^{\circ} \mathrm{C}$, the temperature rise procedure is $35^{\circ} \mathrm{C}$, hold for $10 \mathrm{~min}$, then raise the temperature to $145^{\circ} \mathrm{C}$ at $10^{\circ} \mathrm{C} / \mathrm{min}$ for $2 \mathrm{~min}$, and then raise the temperature to $260^{\circ} \mathrm{C}$ at $20^{\circ} \mathrm{C} / \mathrm{min}$ for $5 \mathrm{~min}$.

\subsection{Microbial Community Analysis}

Microorganisms were analyzed by high-throughput sequencing [15]. On the 148th day of the experiment, samples were taken from the sampling ports at different filtration depths of three biofilters.

\section{Results and Discussion}

\subsection{Analysis of the Removal Effect of Biofilter Pollutants}

\subsubsection{Removal Effect of Conventional Pollutants}

During the test period, Figure 2a shows the change of $\mathrm{NH}_{4}{ }^{+}-\mathrm{N}$ concentration on the inlet and outlet water of the biofilter. The effluent $\mathrm{NH}_{4}{ }^{+}-\mathrm{N}$ concentration of the biofilter gradually stabilizes in about 30 days, and the effluent $\mathrm{NH}_{4}{ }^{+}-\mathrm{N}$ concentration is between 0.14 and $0.47 \mathrm{mg} / \mathrm{L}$, while the $\mathrm{NH}_{4}{ }^{+}-\mathrm{N}$ removal rate is above $60 \%$. The average removal rate of TN in the biofilter is shown in Figure $2 \mathrm{~b}$. The average removal rate of TN in the three filters: Filter C $(28 \%)>$ Filter B $(21 \%)>$ Filter A $(12 \%)(p<0.05)$, and filter C possesses the best nitrogen removal effect. Denitrification produces $\mathrm{N}_{2}$, organic nitrogen or inorganic nitrogen, which is used and transformed by microorganisms into $\mathrm{N}$ element in microbial cells for microbial growth and reproduction, which are all possible ways to remove TN.

After filtration, the turbidity of the effluent from the three filters was significantly reduced (Figure 2c), and the removal effects of filters $B$ and $C$ were better than those of filter A, which is consistent with the previous research conclusions [16,17]. The turbidity of filter $C$ is the lowest, which can meet $80 \%$, indicating that the two-point influent method not only shows no impact on the removal of turbidity but also can further enhance the turbidity removal effect. 

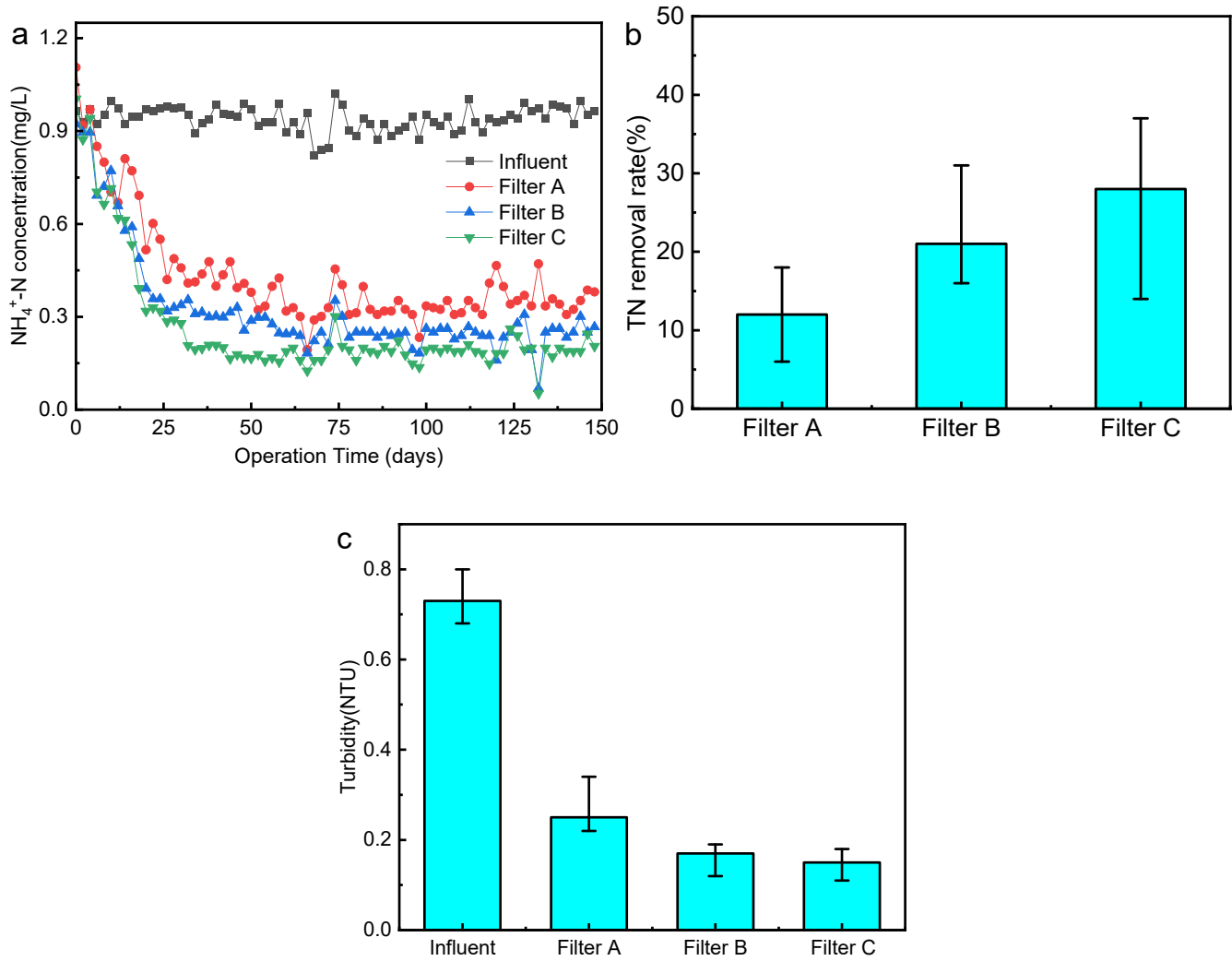

Figure 2. Biofilter (a) $\mathrm{NH}_{4}{ }^{+}-\mathrm{N}$ concentration in influent and effluent $(n=3)$; (b) the average removal rate of TN $(n=3)$; (c) the turbidity of influent and effluent $(n=3)$.

\subsubsection{Removal Effect of Tyrosine and COD}

The average removal rates of Tyr and $\mathrm{COD}_{\mathrm{Mn}}$ in the effluent of the biofilter are shown in Figure 3. During the experiment, the concentration of Tyr in the effluent of the three filters decreased as follows: Filter C $(73 \%)>$ Filter B $(50 \%)>$ Filter A $(20 \%)(p<0.05)$. The Tyr concentration of biofilter effluent is lower than that of influent, which is inconsistent with the conclusion made by Liu et al. [18], who recorded the increase in DON concentration in the effluent after biofiltration in the drinking water treatment plant, indicating that the change of DON overall effluent concentration does not represent the change of individuals, and the change law of different individuals in the filter tank is also different. The change trend of average effluent $\mathrm{COD}_{\mathrm{Mn}}$ removal rate is consistent with that of average effluent Tyr removal rate. The $\mathrm{COD}_{\mathrm{Mn}}$ removal rate can reflect the removal of organic matter in the biofilter. Tyr is an organic matter, and its molecular structure contains reducing phenolic hydroxyl and amino groups, which can be oxidized by potassium permanganate. Therefore, the $\mathrm{COD}_{\mathrm{Mn}}$ removal rate can also be applied as the basis of Tyr removal. Meanwhile, except for the influent mode, other conditions of filter $B$ and $C$ are the same, but the organic matter removal effect of filter $C$ is significantly better than that of filter $B$, indicating that the two-point influent improves the organic matter removal rate of biofilter. 


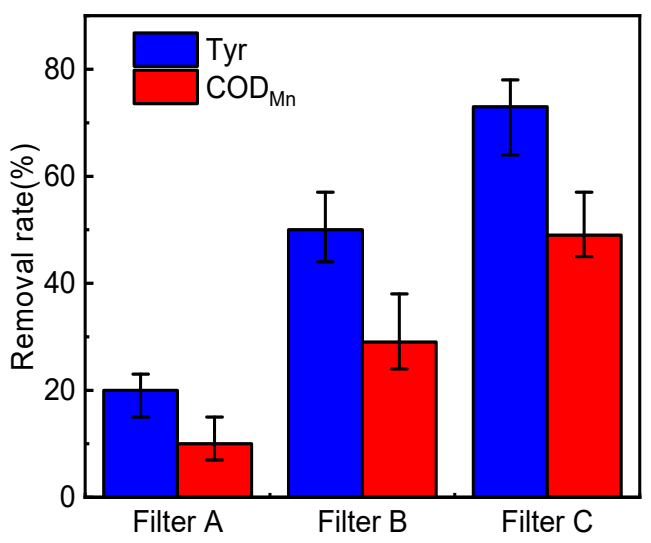

Figure 3. Average removal rates of Tyr and $\mathrm{COD}_{\mathrm{Mn}}$ in the biofilter effluent $(n=3)$.

\subsection{The Formation Potential and Influencing Factors of DCAN in the Effluent of the Biofilter}

The formation potential for DCAN in the influent and effluent of the biofilter is shown in Figure 4a. During the experiment, the formation potential of effluent DCAN was relatively stable, and the formation potential of effluent DCAN decreased to varying degrees after the three filter tanks. The formation potential of DCAN in the effluent of filter $C$ is the lowest, indicating that it has the best effect on removing DCAN precursors. The generation potential for DCAN in the effluent of the three filters lessens from the Tyr concentration. Tyr is a crucial precursor of DCAN [19], and the removal of Tyr can cut down the generation of DCAN in the subsequent disinfection process. The formation potential for DCAN is related to many factors, such as backwashing and operating conditions of the filter [20,21]. Liu et al. [22] found that Soluble microbial products (SMPs) released by bacterial metabolism are considered to be the primary source of DON in drinking water biofilters. The research of Zhou et al. [23] confirmed that $\mathrm{NH}_{4}{ }^{+}-\mathrm{N}, \mathrm{NO}_{3}{ }^{-}-\mathrm{N}$ and $\mathrm{NO}_{2}{ }^{-}-\mathrm{N}$ in water are also important sources of nitrogen in N-DBPs. Therefore, the SMPS produced by the internal microbial action of the biofilter and other organic matter in the effluent and even $\mathrm{NO}_{3}{ }^{-}-\mathrm{N}$ and $\mathrm{NO}_{2}{ }^{-}-\mathrm{N}$ may be the precursors of DCAN, affecting the effluent DCAN formation potential.
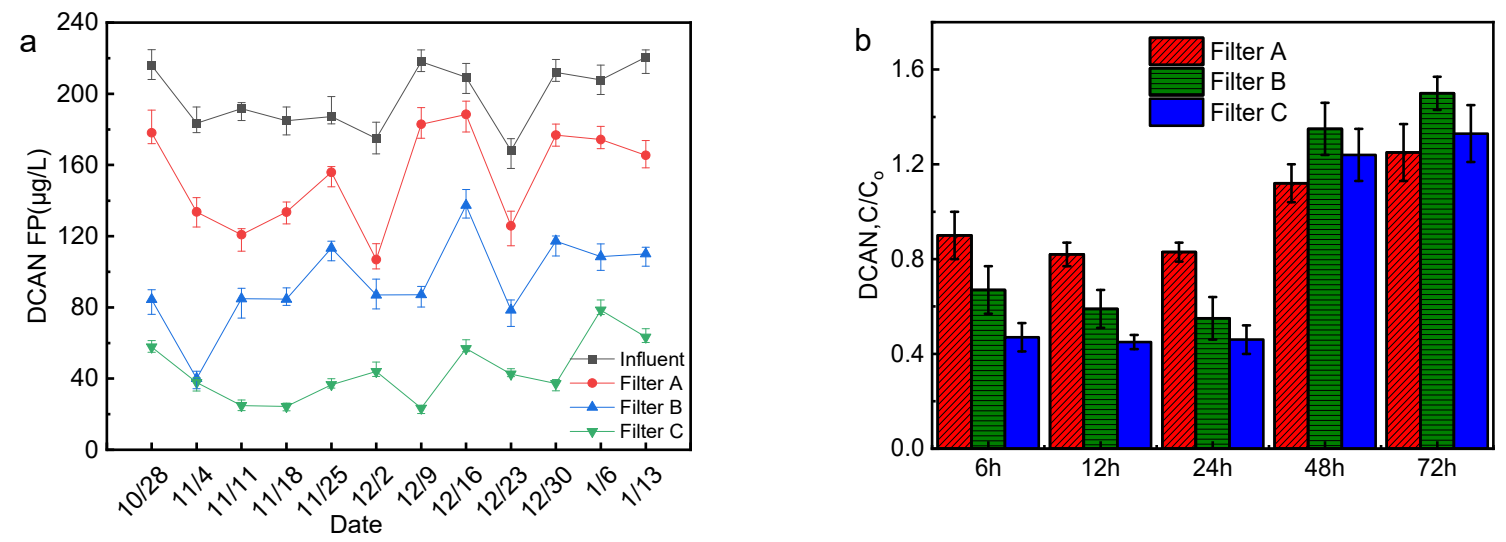

Figure 4. DCAN formation potential of biofilter (a) Influent and effluent $(n=3)$; (b) Changes with backwash time $(n=3)$.

Backwashing will also impact the formation potential for DCAN in the effluent of biofilter. Figure $4 \mathrm{~b}$ shows the changes in the effluent DCAN formation potential with backwashing time. During continuous operation within one backwash cycle $(24 \mathrm{~h})$, the effluent DCAN formation potential is lower than that of the influent water. When the continuous operation time exceeds $24 \mathrm{~h}$, the formation potential for DCAN in the effluent of the three filters increased significantly and was higher than that of the influent. Among 
them, the growth of filters B and C was larger, and the formation potential for DCAN in the effluent exceeded that of filter A. The reason for this phenomenon is that under long-term continuous operation, the adsorption reaches saturation and cannot play a role, the adsorbed pollutants are gradually released, and the SMP produced by microorganisms will accumulate and release. The adsorption performance of activated carbon is stronger than that of quartz sand, and the number and activity of microorganisms in the activated carbon-quartz sand biofilter are also stronger than that of quartz sand biofilter. Therefore, the impact of continuous operation on activated carbon-quartz sand biofilter is higher than that of quartz sand biofilter.

\subsection{Analysis of Changes in Biofilter along the Way}

The changing rules of Tyr concentration along the biofilter are shown in Figure 5a. The Tyr concentration of filters A and B first decreased rapidly and then increased slowly, and this is consistent with the conclusion that the concentration of DON in the biofilter first plunges and then rises slowly. Many studies have shown that the DON concentration first decreases and then increases in the biofilter. For example, Liu et al. [18] found that the DON concentration decreases at $0 \sim 10 \mathrm{~cm}$ and increases at 10 200 cm. Zhang et al. [24] divided the DON concentration change into $0 \sim 20 \mathrm{~cm}$ decrease stage and 20 100 cm increase stage. Liew et al. [25] believe that this is because with the increase in biofilter depth, the biomass and microbial activity of filter materials at different depths first increase and then decrease. Among them, the concentration of Tyr in filter $C$ increased briefly because of the inflow of water at $20 \mathrm{~cm}$, and then dropped to $50 \mathrm{~cm}$ and crept up. The decrease rate of Tyr concentration on the activated carbon layer of filters $B$ and $C$ is much greater than that of filter A; it may be that the activated carbon has a large specific surface area, strong absorption capacity, and more attached microorganisms [26], while the smooth surface of quartz sand is not conducive for microorganisms to attach. The Tyr concentration of filter A is basically unchanged between $30 \sim 100 \mathrm{~cm}$, while that of filter B rises significantly after $50 \mathrm{~cm}$, and the increase in filter $C$ in the second half of the filter is smaller than that of filter $B$. The three filters consume a lot of oxygen in the upper half of the filter material (as is shown in Figure 5b), so the amount of oxygen distributed in the lower layer is reduced, which reduces the number of microorganisms in the lower layer, and the microbial decomposition of Tyr in the lower layer is limited. Previous studies have shown that Tyr is a typical representative of $\mathrm{SMP}_{S}$ released by bacteria [22], so the accumulation of $\mathrm{SMP}_{\mathrm{S}}$ is also the reason for the increase in Tyr concentration in the lower layer of the filter. The influent of filter $\mathrm{C}$ at the depth of $20 \mathrm{~cm}$ brings in DO, which increases the DO at $20 \mathrm{~cm}$ depth (as is shown in Figure 5b), supplements the DO of the lower filter material, improves the microbial environment to a certain extent, and enables microorganisms to play a better role. The rate of decline of filter $C$ in the $20 \sim 50 \mathrm{~cm}$ stage is greater than that of filter $B$, while the rise in the $50 \sim 100 \mathrm{~cm}$ is slower than that of filter $\mathrm{B}$. The biomass of the biofilter changes along the filter material layer depth as shown in Figure 5(c), and the biomass decreases together with the increase in the filter layer depth. The biomass of filter A decreased rapidly, which may be because the surface of the quartz sand is not conducive to the growth of microorganisms. Except for the depth of $0 \sim 10 \mathrm{~cm}$, the biomass of filter $\mathrm{B}$ and $\mathrm{C}$ at the depth of other filter materials is greater than that of filter A. The possible reason is that although the activated carbon has a huge specific surface area, it is mostly concentrated in micropores and is not fully utilized by aerobic microorganisms. Therefore, the biomass of activated carbon layer of filter $B$ and $C$ at $0 \sim 10 \mathrm{~cm}$ is smaller than that of the quartz sand layer of filter $\mathrm{A}$. In the second half of the filter, the microorganisms in filter $\mathrm{B}$ and $\mathrm{C}$ that are not intercepted by activated carbon are intercepted by quartz sand, so the biomass decreases slowly. The biomass of filter $C$ increased temporarily due to the inflow at the depth of $20 \mathrm{~cm}$. 

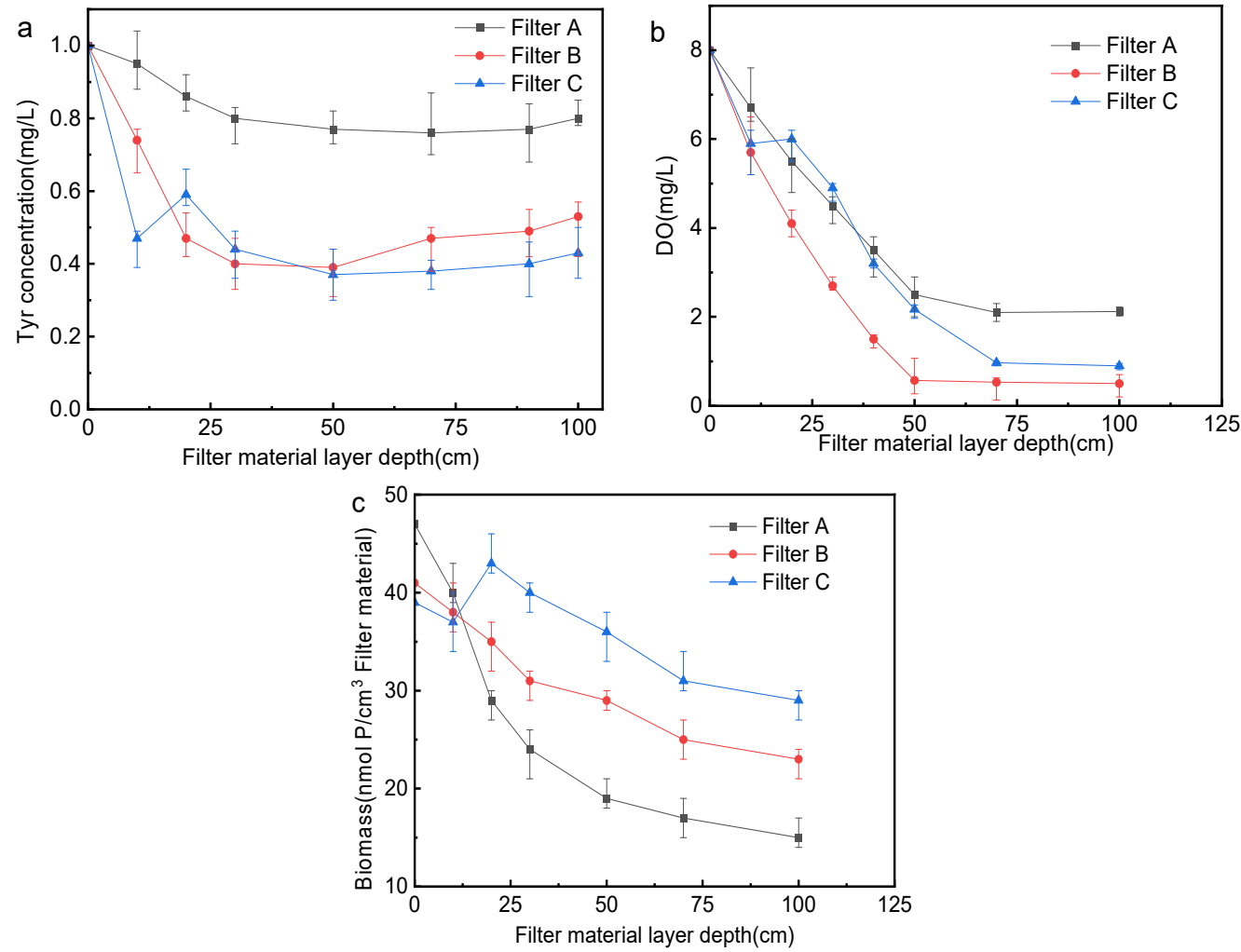

Figure 5. Changes of biofilter along filter material layer depth (a) Tyr $(n=3)$; (b) DO $(n=3)$; (c) Biomass $(n=3)$.

\subsection{Conversion of Nitrogen in the Biofilter}

Nitrogen in drinking raw water mainly exists in the form of $\mathrm{NH}_{4}{ }^{+}-\mathrm{N}, \mathrm{NO}_{2}{ }^{-}-\mathrm{N}, \mathrm{NO}_{3}{ }^{-}-$ $\mathrm{N}$, and organic nitrogen [27]. Most of the organic nitrogen in this experiment is Tyr. In the biofilter, dissolved inorganic nitrogen (DIN) and DON are mutually converted, so it is necessary to discuss the conversion to nitrogen in the biofilter. The changes of nitrogen in the water in and out of the biofilter are shown in Figure 6. The DIN loss is Filter C > Filter $\mathrm{B}>$ Filter A $(p<0.05)$, which is consistent with the removal rate of $\mathrm{COD}_{\mathrm{Mn}}$. The utilization of organic matter by the biofilter increases with the increase of DIN loss, indicating that the DIN loss phenomenon in the reaction is related to filter denitrification [28].

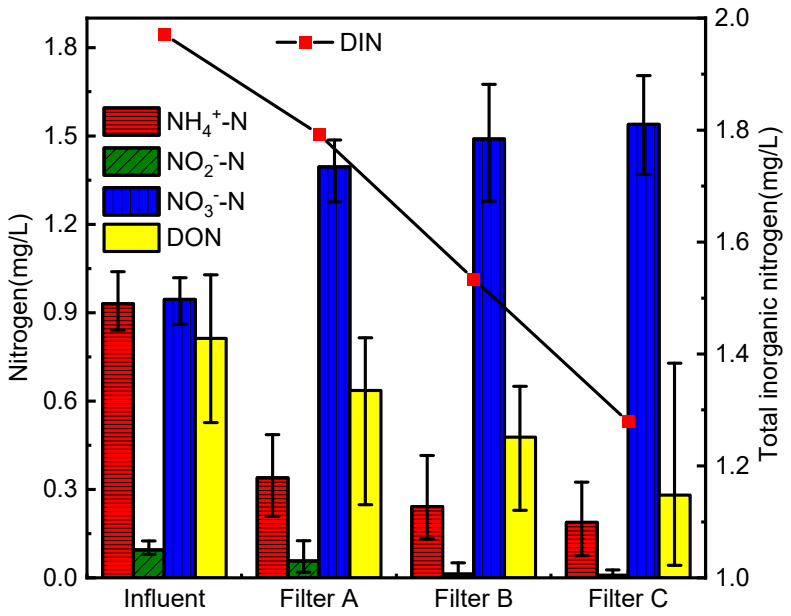

Figure 6. Changes of nitrogen in influent and effluent of biofilter $(n=3)$. 
The reactions related to nitrogen transformation in the biofilter mainly include nitrification, denitrification, ammoniation, and so on. The oxygen in the upper part of the filter is sufficient, and the nitrification reaction is mainly carried out in the upper part of the filter. The oxygen in the lower part of the filter is insufficient, and the denitrification reaction is mainly carried out in the lower part of the filter. The ammoniation of Tyr degradation can occur in all stages along the biofilter, and the reaction generates ammonia nitrogen to realize the transformation from organic nitrogen to inorganic nitrogen. Denitrification produces $\mathrm{N}_{2}$, and microbial growth in the filter consumes some $\mathrm{N}$ elements, which will cause DIN loss. At the same time, organic nitrogen conversion will make up for DIN loss to a certain extent. There is a certain linear correlation between the variation of Tyr in the effluent of the three biofilters and the nitrogen loss in the filter, and the correlation coefficients of the biofilters are: Filter A (0.44), Filter B (0.63) and Filter C (0.73). The correlation coefficients of biofilters are between 0.3 and 0.8 , indicating that there is a certain correlation between the loss of DIN and the change of Tyr in the three biofilters. Some scholars have confirmed that the amount of DIN loss is positively correlated with $\mathrm{NH}_{4}{ }^{+}-\mathrm{N}$ concentration, and increases with the increase of $\mathrm{NH}_{4}{ }^{+}-\mathrm{N}$ concentration [29]. From the correlation coefficient, it can be known that the loss of DIN in this experiment is positively correlated with the change of Tyr, so there is a certain relationship between the change of Tyr and the concentration of $\mathrm{NH}_{4}{ }^{+}-\mathrm{N}$. it is speculated that Tyr will be degraded by ammoniation in the biofilter to produce $\mathrm{NH}_{4}{ }^{+}-\mathrm{N}$. It is confirmed from the side that part of Tyr is removed by ammoniation. In the meantime, it is only correlated but not strongly correlated, indicating that Tyr can also be removed by other means. Among the three types of filters, filter $\mathrm{C}$ has the strongest correlation, and filter A has the weakest correlation.

\subsection{Analysis of the Microbial Community in the Biofilter}

\subsubsection{Species Diversity Analysis}

It's shown in Table 2 for the species diversity index of samples from different biofilters and different filter layer heights. The larger the Shannon index, the higher the community diversity. The larger the Chao index, the higher the species richness. At different filter depths, the Shannon index and Chao index of filter $C$ are higher than those of other filters, indicating that its species diversity and richness are the highest. Previous studies have shown that higher microbial diversity and richness are conducive to microbial degradation $[30,31]$, which also explains why the degradation rate of organic matter in filter $\mathrm{C}$ and the removal rate of Tyr are the highest.

Table 2. Alpha diversity index of biofilter samples.

\begin{tabular}{cccc}
\hline Sample & Shannon Index & Chao1 Index & Good's Coverage \\
\hline S-1 & 2.64 & 675.56 & 1 \\
S-2 & 2.39 & 616.13 & 1 \\
S-3 & 2.49 & 716.13 & 1 \\
S-4 & 2.28 & 606.36 & 1 \\
TSa-1 & 2.85 & 611.37 & 1 \\
TSa-2 & 3.15 & 788.4 & 1 \\
TSa-3 & 2.91 & 697.33 & 1 \\
TSa-4 & 3.77 & 774.23 & 1 \\
TSb-1 & 2.82 & 584.03 & 1 \\
TSb-2 & 2.3 & 522.67 & 1 \\
TSb-3 & 2.74 & 649.96 & 1 \\
TSb-4 & 3.14 & 680.51 & 1 \\
\hline
\end{tabular}

Note: S-1, S-2, S-3, and S-4 indicate the filter material of the quartz sand biofilters at a distance of 10, 20, 50, and $100 \mathrm{~cm}$ from the surface; TSa-1, TSa-2, TSa-3, and TSa-4 represent the filter layer material at a distance of 10, 20, 50, and $100 \mathrm{~cm}$ from the surface of the two-point influent activated carbon-quartz sand biofilter; TSb-1, TSb-2, TSb-3, and TSb-4 represent the distance of the activated carbon-quartz sand biofilter. The filter material of the filter layer at the surface of $10,20,50$, and $100 \mathrm{~cm}$, and the rest of the table is the same as the figure. 


\subsubsection{Analysis of Microbial Community Structure at the Phylum Level}

The microbial community structure of the sample of the phylum level is shown in Figure 7. A total of seven main phyla were detected in samples of different biofilters, namely Proteobacteria, Planctomycetes, Bacteroidetes, Firmicutes, Chloroflexi, Actinobacteria, and Chlorobi, among which, Proteobacteria can use organic matter as nutrition [32], participating in the degradation of a series of multifunctional aromatic protein substances [33]. Bacteroidetes is also considered to be very important to the degradation process of organic matter [34]. Studies have shown that Actinobacteria can also remove nitrogen-containing organic matter, so it is speculated that they are related to the degradation and removal of Tyr. The bacterial phylum involved in the removal of Tyr in the sample is discussed and analyzed separately, as shown in Figure 8. The changes along the way in abundance of bacteria in the Tyr-related phylum of the three filters are consistent with the changes in the Tyr along the way in the figure, indicating that the removal of Tyr is closely related to the microorganisms in the biofilter. By comparing the abundance changes along the way between filter $\mathrm{B}$ and filter $\mathrm{C}$, the two-point influent has improved the phenomenon that the bacterial abundance related to the removal of Tyr in the activated carbon-quartz sand biofilter decreases significantly in the lower half of the filter, which is also the reason why the Tyr concentration of filter $B$ increases significantly in the lower half. At the same time, the abundance of bacteria related to Tyr removal is evenly distributed in the filter, which ensures the stability and high efficiency of Tyr removal.

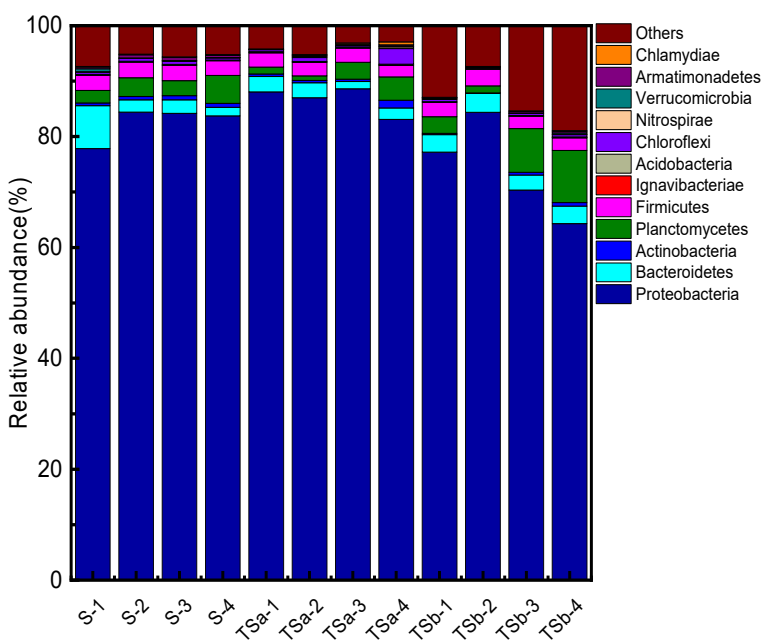

Figure 7. Horizontal community structure distribution of bacterial phyla in biofilter samples.

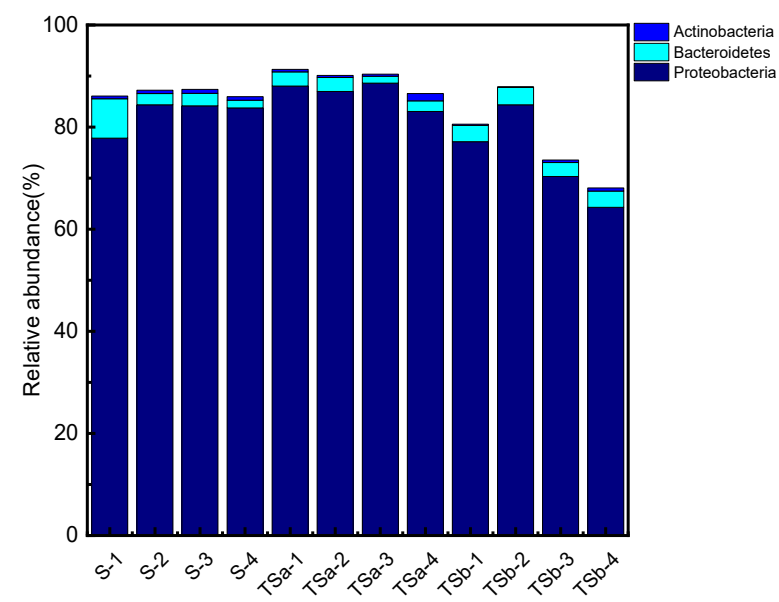

Figure 8. Removal of Tyr-related microbiota. 


\title{
4. Conclusions
}

The two-point influent activated carbon-quartz sand biofilter is superior to other filters in removing conventional pollutants $\left(\mathrm{NH}_{4}{ }^{+}-\mathrm{N}\right.$ and turbidity) and organic pollutants $\left(\mathrm{COD}_{\mathrm{Mn}}\right.$ and Tyr); the average $\mathrm{NH}_{4}{ }^{+}-\mathrm{N}$ removal rate is $80 \%$, turbidity is $80 \%, \mathrm{COD}_{\mathrm{Mn}}$ is $49 \%$, and Tyr is $73 \%$. The two-point influent activated carbon-quartz sand biofilter has the best control effect on the formation of DCAN. The removal of Tyr in the biofilter is concentrated on $0 \sim 30 \mathrm{~cm}$ in the upper part of the filter. DO decreases along the upper part of the filter, and then stabilizes, and the total biomass of the two-point influent charcoalsand biofilter is the largest. The correlation coefficient between DIN loss and Tyr change in the two-point influent activated carbon-quartz sand biofilter is 0.73 , which possesses the highest correlation, and its biochemical property is the highest, which is beneficial to the removal of precursors. The total abundance of bacteria related to Tyr removal in two-point influent activated carbon-quartz sand biofilter is the highest among the three filters.

\begin{abstract}
Author Contributions: Conceptualization, H.Z. and X.G.; methodology, X.G.; validation, H.Z.; formal analysis, B.J.; investigation, X.G.; resources, H.Z. and X.G.; data curation, X.G.; writing-original draft preparation, X.G.; writing-review and editing, H.Z., J.M., M.X. and M.Y.; visualization, X.G.; supervision, H.Z.; project administration, H.Z.; funding acquisition, H.Z. and Y.L. All authors have read and agreed to the published version of the manuscript.
\end{abstract}

Funding: This research was funded by the Zhejiang Provincial Natural Science Foundation of China (LGF20E080003), the Public Benefits Projects of Ningbo (202002N3055), and Ningbo Science and Technology Bureau (202003N4312, 2021J162).

Institutional Review Board Statement: Not applicable.

Informed Consent Statement: Not applicable.

Data Availability Statement: The data presented in this study are available on request from the corresponding author.

Conflicts of Interest: The authors declare no conflict of interest.

\section{References}

1. Richardson, S.D.; Plewa, M.J.; Wagner, E.D.; Schoeny, R.; DeMarini, D.M. Occurrence, genotoxicity, and carcinogenicity of regulated and emerging disinfection by-products in drinking water: A review and roadmap for research. Mutat. Res./Rev. Mutat. Res. 2007, 636, 178-242. [CrossRef] [PubMed]

2. $\quad$ Dong, Y.; Li, F.; Shen, H.J.; Lu, R.Z.; Yin, S.Q.; Yang, Q.; Li, Z.F.; Wang, S.H. Evaluation of the water disinfection by-product dichloroacetonitrile-induced biochemical, oxidative, histopathological, and mitochondrial functional alterations: Subacute oral toxicity in rats. Toxicol. Ind. Health 2018, 34, 158-168. [CrossRef]

3. Ding, S.; Chu, W.H.; Bond, T.; Wang, Q.; Gao, N.Y.; Xu, B.; Du, E. Formation and estimated toxicity of trihalomethanes, haloacetonitriles, and haloacetamides from the chlor(am)ination of acetaminophen. J. Hazard. Mater. 2017, 341, 112-119. [CrossRef] [PubMed]

4. Chu, W.H.; Gao, N.Y.; Yin, D.Q. Control Countermeasures of new halogenated nitrogen containing disinfection by-products in drinking water. In Proceedings of the 6th International Conference on Intelligent Systems and Knowledge Engineering, Shanghai, China, 22-24 September 2011.

5. Chu, W.H.; Gao, N.Y.; Zhao, S.J.; Deng, H.P. Mechanism analysis of chloroform formation by tyrosine chlorination of typical dissolved organic nitrogen in drinking water. J. Chem. 2009, 67, 2505-2510.

6. Srithep, S.; Phattarapattamawong, S. Kinetic removal of haloacetonitrile precursors by photo-based advanced oxidation processes $\left(\mathrm{UV} / \mathrm{H}_{2} \mathrm{O}_{2}, \mathrm{UV} / \mathrm{O}_{3}\right.$, and $\left.\mathrm{UV} / \mathrm{H}_{2} \mathrm{O}_{2} / \mathrm{O}_{3}\right)$. Chemosphere 2017, 176, 25-31. [CrossRef] [PubMed]

7. Cuthbertson, A.A.; Kimura, S.Y.; Liberatore, H.K.; Knappe, D.R.U.; Richardson, S.D. GAC to BAC: Does it make chloraminated drinking water safer? Water Res. 2020, 172, 115432. [CrossRef] [PubMed]

8. Xiang, H.; Lu, X.W.; Yin, L.H.; Yang, F.; Zhu, G.C.; Liu, W.P. Microbial community characterization, activity analysis and purifying efficiency in a biofilter process. J. Environ. Sci. 2013, 25, 677-687. [CrossRef]

9. Liu, C.; Olivares, C.I.; Pinto, A.J.; Lauderdale, C.V.; Brown, J.; Selbes, M.; Karanfil, T. The control of disinfection byproducts and their precursors in biologically active filtration processes. Water Res. 2017, 124, 630-653. [CrossRef]

10. Zhang, H.N.; Gu, L.; Liu, B.; Gan, H.H.; Yu, X. An improved biofilter to control the dissolved organic nitrogen concentration during drinking water treatment. Environ. Sci. Pollut. Res. Int. 2016, 23, 18137-18144. [CrossRef]

11. Thurman, E.M. Organic Geochemistry of Natural Waters. Geochim. Et Cosmochim. Acta. 1986, 50, 2119. 
12. Gu, L.; Liu, B.; Yu, X. Dissolved organic nitrogen (DON) in the processes of polluted source water treatment. Chin. Sci. Bull. 2010, 55, 3098-3101. [CrossRef]

13. Yu, X.; Zhang, X.J.; Wang, Z.S. Determination of biomass in biological treatment of drinking water by lipid phosphorus method Water Supply Drain. 2002, 28, 5.

14. Compton, O.C.; Jain, B.; Dikin, D.A.; Abouimrane, A.; Amine, K.; Nguyen, S.T. Chemically active reduced graphene oxide with tunable C/O ratios. ACS Nano 2011, 5, 4380-4391. [CrossRef]

15. Miao, L.; Wang, S.Y.; Li, B.K.; Cao, T.H.; Zhang, F.Z.; Wang, Z.; Peng, Y.Z. Effect of carbon source type on intracellular stored polymers during endogenous denitritation (ED) treating landfill leachate. Water Res. 2016, 100, 405-412. [CrossRef] [PubMed]

16. Fan, P.; Wu, C.D.; Lu, S.M.; Zhang, F. Treatment of micro polluted raw water by GAC quartz sand biofilter. Water Treat. Technol. 2008, 34, 59-62.

17. Yang, Y.L.; Li, X.; Zhang, Y.; Li, G.B. Experimental study on the efficiency of Biofilter in treating micro polluted water. Ind. Water Treat. 2007, 27, 17-20.

18. Liu, B.; Gu, L.; Yu, X.; Yu, G.Z.; Zhao, C.M.; Li, Q.F.; Zhai, H.M. Profile of dissolved organic nitrogen (DON) in full-scale ozone and biological activated carbon filter. Desalin. Water Treat. 2015, 55, 2069-2078. [CrossRef]

19. Jia, A.; Wu, C.; Duan, Y. Precursors and factors affecting formation of haloacetonitriles and chloropicrin during chlor(am)ination of nitrogenous organic compounds in drinking water. J. Hazard. Mater. 2016, 308, 411-418. [CrossRef]

20. Tan, Y.W.; Lin, T.; Jiang, F.C.; Dong, J.; Chen, W.; Zhou, D.J. The shadow of dichloroacetonitrile (DCAN), a typical nitrogenous disinfection by-product (N-DBP), in the waterworks and its backwash water reuse. Chemosphere 2017, 181, 569-578. [CrossRef]

21. Lemus-pérez, M.; Susa, M.R. The effect of operational conditions on the disinfection by-products formation potential of exopolymeric substances from biofilms in drinking water-ScienceDirect. Sci. Total Environ. 2020, 748, 141148. [CrossRef]

22. Liu, B.; Gu, L.; Yu, X.; Zhang, H.N. Dissolved organic nitrogen (DON) in a full-scale drinking water treatment plant. J. Water Supply Res. Technol.-AQUA 2012, 61, 41-49. [CrossRef]

23. Zhou, S.Q.; Wu, Y.T.; Zhu, S.M.; Sun, J.L.; Bu, L.J.; Dionysiou, D.D. Nitrogen conversion from ammonia to trichloronitromethane: Potential risk during UV/chlorine process. Water Res. 2020, 172, 115508. [CrossRef]

24. Zhang, H.N.; Zhang, K.F.; Jin, H.X.; Gu, L.; Yu, X. Variations in dissolved organic nitrogen concentration in biofilters with different media during drinking water treatment. Chemosphere 2015, 139, 652-658. [CrossRef] [PubMed]

25. Liew, D.; Linge, K.L.; Heitz, A.; Joll, C.A. Nitrogenous DBPs in drinking water: Toxicity, regulation, analysis, occurrence and control. Disinfect. By-Prod. Hum. Health 2012, 7, 83-124.

26. Chu, W.H.; Gao, N.Y.; Deng, Y.; Krasner, S.W. Precursors of Dichloroacetamide, an Emerging Nitrogenous DBP Formed during Chlorination or Chloramination. Environ. Sci. Technol. 2010, 44, 3908-3912. [CrossRef] [PubMed]

27. Westerhoff, P.; Mash, H. Dissolved organic nitrogen in drinking water supplies: A review. J. Water Supply Res. Technol.-AQUA 2002, 51, 415-448. [CrossRef]

28. Krasner, S.W.; Weinberg, H.S.; Richardson, S.D.; Pastor, S.J.; Chinn, R.; Sclimenti, M.J.; Onstad, G.D.; Thruston, A.D. Occurrence of a New Generation of Disinfection Byproducts. Environ. Sci. Technol. 2006, 40, 7175-7185. [CrossRef]

29. Liu, B.; Fan, H.; Yu, G.Z.; Yu, X.; Zhao, C.M.; Li, Q.F.; Zhang, S.T.; Wei, B. Removal mechanism of ammonia nitrogen in drinking water biofilter. Environ. Sci. 2012, 33, 9.

30. Fan, Z.H.; Yang, H.L.; Li, S.F.; Yu, X. Tracking and analysis of DBP precursors' properties by fluorescence spectrometry of dissolved organic matter-ScienceDirect. Chemosphere 2020, 239, 124790. [CrossRef] [PubMed]

31. Boon, N.; Pycke, B.F.G.; Marzorati, M.; Hammes, F. Nutrient gradients in a granular activated carbon biofilter drives bacterial community organization and dynamics. Water Res. 2011, 45, 6355-6361. [CrossRef]

32. Ferrer-Polonio, E.; Mendoza-Roca, J.A.; Iborra-Clar, A.; Alonso-Molina, J.L.; Pastor-Alcaniz, L. Comparison of two strategies for the start-up of a biological reactor for the treatment of hypersaline effluents from a table olive packaging industry. Chem. Eng. J. 2015, 273, 595-602. [CrossRef]

33. Song, W.L.; Lee, L.Y.; You, H.; Shi, X.Q.; Ng, H.Y. Microbial community succession and its correlation with reactor performance in a sponge membrane bioreactor coupled with fiber-bundle anoxic bio-filter for treating saline mariculture wastewater-ScienceDirect. Bioresour. Technol. 2020, 295, 122284. [CrossRef] [PubMed]

34. Cappello, S.; Volta, A.; Santisi, S.; Morici, C.; Mancini, G.; Quatrini, P.; Genovese, M.; Yakimov, M.M.; Torregrossa, M. Oildegrading bacteria from a membrane bioreactor (BF-MBR) system for treatment of saline oily waste: Isolation, identification and characterization of the biotechnological potential. Int. Biodeterior. Biodegrad. 2016, 110, 235-244. [CrossRef] 